\title{
Gestational trophoblastic disease: our patients deserve better case detection and follow up
}

Clinical suspicion, correct histological diagnosis and follow up are mandatory

The World Health Organisation's (WHO) classification of gestational trophoblastic disease includes complete, partial, invasive and metastatic hydatidiform mole, exaggerated placental site nodule or plaque and two malignant tumours- placental site trophoblastic tumour and choriocarcinoma [1].

The incidence of gestational trophoblastic disease (GTD) in Sri Lanka according to a hospital based study is 1 in 213 pregnancies [2] as compared to 1 in 2000 pregnancies in the USA [3]. Complete moles (CMs) are more common in Asian women [4]. The incidence of partial moles (PMs) is similar to that of CMs. PMs tend to be less often recognised clinically or pathologically, since their appearances are more subtle and easily misinterpreted as a spontaneous abortion by clinicians or as 'products of conception' by pathologists. Ideally, all tissue from a spontaneous abortion in the first trimester should be sent for histological examination for evidence of GTD.

Hydatidiform moles invade the myometrium (invasive mole), metastasise (metastasising mole) or become malignant (choriocarcinoma). These complications are more common in complete moles (20-30\%) [5], but rarely occur in partial moles (1-5\%) [6]. Chemotherapy for molar pregnancies after persistently abnormal $\beta$-human chorionic gonadotrophin $(\beta-h \mathrm{CG})$ levels has resulted in a marked decline in invasive moles and choriocarcinoma [7], so that accurate histological diagnosis of the molar type and differentiation from a hydropic and other aneuploid abortions are important [8]. Diagnosis of a non-molar pregnancy as a molar pregnancy has serious consequence on women who may wish to conceive, as $\beta$-hCG monitoring and contraception are advised, and elevation of $\beta$-hCG from a new pregnancy or persistent trophoblastic disease cannot be differentiated.

All molar pregnancies result from abnormal fertilisation. CM results from a purely paternal conceptus, due to loss of maternal nuclear material or fertilisation of an empty egg devoid of maternal chromosomes by a single spermatozoon ( $90 \%$ of cases), which may duplicate to produce a $46 \mathrm{XX}$ homozygous mole, or by fertilisation by two sperms (10\% of cases) resulting in a dispermic $46 \mathrm{XX}$ or 46XY heterozygous mole [9]. PM results from conceptions when two chromosomal complements come from the father and one from the mother, resulting in triploidy (69XXY, 69XXX or 69XYY). Rarely PMs are tetraploid with three paternal complements [10].

CM and PM differ in their clinical presentation, behaviour and pathological features. $\mathrm{CM}$ is common in women at the two ends of the reproductive age, and in women with a previous mole. They present in the late part of the first trimester or early second trimester with increased uterine size for dates, anaemia, pre-eclampsia, hyperemesis gravidarum, hyperthyroidism and theca lutein cysts. Patients have markedly elevated $\beta$-hCG levels.

The use of high quality ultrasound performed by transvaginal probes for prenatal obstetric dating and in patients presenting with abdominal pain or vaginal bleeding, has resulted in early identification of first trimester complications, including molar pregnancies. Abnormal pregnancies are terminated at 8-12 weeks of gestational age and these are not clinically suspected to be moles [11]. Before $1980 \mathrm{CMs}$ were evacuated at a mean gestational age of 16 weeks, and currently most CMs are terminated at 8-12 weeks [3]. PMs are usually not suspected clinically but present as missed abortions with late first trimester bleeding and a small uterus for gestational age. Routine investigations should include full blood counts, liver function tests, serum $\beta$-hCG and thyroid function tests.

Macroscopically, the presence of vesicles in an abortion is highly suspicious of a molar pregnancy. In a $\mathrm{CM}$, transparent grape-like vesicles measuring $1-2 \mathrm{~cm}$ in diameter are seen in gestations of 12 weeks or more. 
CM is characterised microscopically by the absence of an amnion and embryo. Chorionic villi are large and polypoidal with invaginations and branching secondary villi. The stroma is mucoid and contains spindle cells. At 6 to 7 weeks, blood vessels are present with no fetal blood cells and disappear gradually with development of diffuse villous hydrops and central cistern formation after 12 weeks [12]. Excessive trophoblastic proliferation consisting of cytotrophoblasts, intermediate and syncytiotrophoblasts is the most characteristic feature in CM. Some villi are completely or partly surrounded by more than two layers of trophoblasts in contrasts to polar trophoblastic proliferation of normal early placentas. Mitotic activity, nucleomegaly and marked hyperchromasia are common in CM but uncommon in PM. In early CM a combination of large hydropic and small non-hydropic and secondary villi are seen often leading to an erroneous diagnosis of a PM [12].

The PM specimens consist of normal appearing immature placental tissue admixed with occasional small molar vesicles. Microscopically fetal tissue, open vessels with nucleated red cells, amnion with a thick basement membrane is seen. There are two populations of villi, consisting of hydropic villi containing occasional central cisterns with multifocal mild to moderate trophoblastic hyperplasia, and normal size villi with a sclerotic or hyalinised stroma. The trophoblastic excess is predominantly syncytiotrophoblasts and focal. Women with CM often have markedly elevated serum $\beta$-hCG levels; however, women with PM have a normal to slightly elevated serum $\beta$-hCG level for gestational age [13].

Hydropic abortions (HA) and other aneuploid abortions can be mistaken for molar pregnancies. HA is a morphologically abnormal placenta with gross or microscopic villous hydrops. Fetal tissue is not usually present. There is no trophoblastic hyperplsia. In most of these patients $\beta$-hCG becomes normal within 4 weeks after evacuation of the abortion and no hormonal evaluation is necessary [13].

The management of $\mathrm{CM}$ and PM are similar, with monitoring of serial $\beta$-hCG measurements weekly until negative and then monthly for 6 months. Most women have spontaneous remission of $\beta$-hCG production. Patients are instructed to avoid conception during the follow up period. If the $\beta$-hCG levels fail to decline for three consecutive weeks or begin to rise at any point, clinical evaluation is done, and includes a repeat curettage. A rise in $\beta$-hCG levels implies persistent GTD and chemotherapy is instituted. The most commonly used prognostic scoring system is that developed by the WHO [1]. It incorporates age, type of antecedent pregnancy, interval between antecedent pregnancy and start of chemotherapy, pretreatment $\beta$-hCG level, ABO blood group of patient and her partner, largest tumour size, site and number of metastasis and previous chemotherapy failure [14]. Since normal trophoblasts naturally invade maternal blood vessels, metastatic disease involves haematogenous spread to the lungs, brain or vagina. Treatment is with a single agent or multi-agent chemotherapy. Treatment does not appear to increase a woman's risk of subsequently delivering an abnormal foetus [13].

Invasive $\mathrm{CM}$ refers to penetration of the myometrial wall by trophoblastic tissue. This is diagnosed by obstetric ultrasonography. Uterine invasion may be so extensive that molar villi are seen on the uterine serosa. A small proportion of women with CM will develop choriocarcinoma. This tumour can occur following a normal pregnancy or a spontaneous abortion. The incidence in the USA is about 1 in 24000 pregnancies [15]. The presenting features are abnormal vaginal bleeding and symptoms from metastatic tumour involvement. Choriocarcinoma is highly sensitive to chemotherapy with cure rates exceeding $95 \%$ even with widespread metastases.

Microscopically it is a biphasic tumour of pleomorphic mononuclear cytotrophoblasts and intermediate trophoblasts with patchy foci of syncytiotrophoblasts, with extensive areas of haemorrhage and necrosis. Villi are absent. Vascular invasion occurs early in tumour development and usually is extensive [13].

Placental site trophoblastic tumour is an uncommon malignant monomorphic tumour of intermediate trophoblasts, with a potential to recur and metastasise. This may follow a normal pregnancy, abortion or a CM. Women present with abnormal vaginal bleeding or amenorrhea. $\beta$-hCG levels are only slightly elevated. Metastatic sites include lungs, pelvis, retroperitoneum and supraclavicular lymph nodes. This tumour is resistant to conventional chemotherapy and radiotherapy [13].

Clinical suspicion, correct histological diagnosis and follow up of patients with GTD are mandatory for early detection of persistent trophoblastic disease and therapy to prevent complications. Ideally all tissue from first trimester abortions should be sent for histological examination and doubtful cases should have DNA and cytogenetic analysis. A separate register for patients with GTD in gynaecological follow up clinics should be maintained.

\section{References}

1. World Health Organisation Scientific Group. Gestational Trophoblastic Disease, Technical Report Series 692. Geneva. World Health Organization, 1983: 1-81.

2. Peris BAK, Goonewardene IMR. Gestational trophoblastic disease. Sri Lanka Journal of Obstetrics and Gynaecology 1991; 5: 40-7.

3. Coukos G, Makrigiannakis A, Chung J, Randall TC, Rubin $\mathrm{SC}$, et al. Complete hydatidiform mole: a disease with a changing profile. Journal of Reproductive Medicine 1999; 44: 698-704.

4. Mungan T, Kuscu E, Dabakoglu T. Hydatidiform mole. Clinical analysis of 310 patients. International Journal of Gynecologic Pathology 1996; 52: 233-6. 
5. Lurian RJ, Brewer JI, Torok EE, Halpern B. Natural history of hydatidiform mole after primary evacuation. American Journal of Obstetrics and Gynecology 1983; 145: 591-5.

6. Bagshawe KD, Lawler SD, Paradinas FJ, Dent J, Browne $\mathrm{P}$, et al. Gestational trophoblastic tumours following initial diagnosis of partial hydatidiform mole. Lancet 1990; 335 : 1074-6.

7. Bagshawe KD, Dent J, Webb JH. Hydatidiform moles in England and Wales 1973-1983. Lancet 1986; 11: 673-7.

8. Howat AJ, Beck S, Fox H. Can histopathologists reliably diagnose molar pregnancy? Journal of Clinical Pathology 1993; 46: 599-602.

9. Jacobs PA, Wilson CM, Sprenkle JA, Rosenshein NB, Migeon BR et. al. Mechanism of origin of complete hydatidiform moles. Nature 1980; 286: 714-6.

10. Lawler SD, Fisher RA, Dent J. A prospective genetic study of complete and partial hydatidiform moles. American Journal of Obstetrics and Gynecology 1991; 164: 1270-7.
11. Mosher R, Goldstein DP, Berkowitz R, Bernstein M, Genest DR. Complete hydatidiform mole: comparison of clinicopathological features, current and past. Journal of Reproductive Medicine 1998; 43: 21-7.

12. Paradinas FJ. The histological diagnosis of hydatidiform moles. Current Diagnostic Pathology 1994; 1: 24-31

13. Janice M, Lage MD. Gestational trophoblastic disease. In: Robby SJ, Anderson MC, Russel P. eds. Pathology of the Female Reproductive Tract. London: Churchill Livingstone 2002, 759-82.

14. Newlands ES, Bower M, Holden L, Short D, Seckl MJ, et al. Management of resistant gestational trophoblastic tumors. Journal of Reproductive Medicine 1998; 43: 111-8.

15. Brenton CA, Brackes MB, Connelly RR. Choriocarcinoma incidence in the USA. American Journal of Epidemiology 1986; 123: 1095-7.

Modini MA Jayawickrama, Histopathologist, Base Hospital, Negombo, Sri Lanka. Tel: +94 112 554692, e-mail: <modinijayawickrama@hotmail.com> (Competing interests: none declared).

\section{Requiem}

Under the wide and starry sky

Dig the grave and let me lie.

Glad did I live, and gladly die,

And I laid me down with a will.

This be the verse you grave for me:

Here he lies where he longed to be;

Home is the sailor, home from the sea,

And the hunter home from the hill,

One of the inscriptions on the gravestone of Robert Louis Stevenson (1850 - 1894), buried on the remote summit of Vasa, a mountain range in the island of Samoa. This inscription, titled Requiem, was written during his life by Stevenson himself. The Samoan inscription reads: The Tomb of Tusitala. Tusitala means "story-teller" in Samoan. (Editor, CMJ). 